\title{
Control of hypercalcaemia in thyrotoxicosis
}

\author{
M. K. JONES \\ M.R.C.P. \\ S. E. Papapoulos \\ M.D.
}

Department of Medicine, The Middlesex Hospital, London WIN 8AA

\begin{abstract}
Summary
Two thyrotoxic patients with significant hypercalcaemia are described. The hypercalcaemia failed to suppress with hydrocortisone, propranolol and calcitonin but serum calcium fell rapidly to normal with carbimazole treatment. Both patients were subsequently treated surgically and at operation no evidence of parathyroid disease was found. Thyroid disease must be controlled before co-existing parathyroid disease is diagnosed in hypercalcaemic thyrotoxic patients.
\end{abstract}

\section{Introduction}

Hypercalcaemia can be associated with thyrotoxicosis, although the mechanism is not fully understood. The steroid suppression test is used to differentiate hypercalcaemia of parathyroid origin from hypercalcaemia of other causes (Dent and Watson, 1968); the authors describe 2 thyrotoxic patients with hypercalcaemia which failed to be suppressed with steroids, but responded to carbimazole.

\section{Case Histories}

\section{Case 1}

A 35-year-old woman presented with a 13-year history of a lump in the neck. On examination there were no signs of hyperthyroidism but there was a firm mobile swelling in the right lobe of the thyroid. The diagnosis of thyrotoxicosis was established biochemically: serum $\mathrm{T}_{4},>250 \mathrm{nmol} / \mathrm{l}$; free thyroxine index (FTI), $>250 ; \mathrm{T}_{3}, 3.1 \mathrm{nmol} / \mathrm{l}$. Serum calcium was raised, $2 \cdot 7-2 \cdot 8 \mathrm{mmol} / \mathrm{l}$; serum phosphate was $1.1 \mathrm{mmol} / 1$ and urinary calcium was 10.0 $\mathrm{mmol} / 24 \mathrm{hr}$. Skeletal survey showed no evidence of metabolic bone disease. ${ }^{89} \mathrm{Tc}$ scan and ultrasound demonstrated a solid lesion with decreased uptake in a multinodular goitre. Hydrocortisone $120 \mathrm{mg}$ daily was given for 10 days but serum calcium failed to decrease; propranolol $60 \mathrm{mg}$ daily for 14 days also had no effect on serum calcium. When carbimazole was administered (45 mg daily) serum calcium rapidly fell to normal. The response to treatment is shown in Fig. 1. Serum parathyroid hormone before treatment was undetectable $(<0.15 \mathrm{ng} / \mathrm{ml})$ but rose within the normal range to $0.5 \mathrm{ng} / \mathrm{ml}$ on normalization of the serum calcium after 7 days' carbimazole - therapy. Urinary calcium excretion also returned to normal.

A sub-total thyroidectomy was performed and a differentiated follicular carcinoma was removed; 4 normal parathyroid glands were also identified. The patient subsequently remained normocalcaemic.

\section{Case 2}

A 32-year-old man presented with a 3-month history of lassitude, weight loss, polyuria and polydipsia. Calcium was deposited in the cornea and adjacent sclera of both eyes. The patient was clinically thyrotoxic with an enlarged firm goitre and an obvious bruit. Serum $T_{4}$ was $>250 \mathrm{nmol} / 1$ and FTI $>250$. Serum calcium was $3 \cdot 2-3 \cdot 3 \mathrm{mmol} / \mathrm{l}$; serum phosphate $1.2 \mathrm{mmol} / \mathrm{l}$, urinary calcium 32.5 $\mathrm{mmol} / 24 \mathrm{hr}$ and blood urea $12.0 \mathrm{mmol} / 1$. Skeletal survey showed no signs of metabolic bone disease. Hydrocortisone $120 \mathrm{mg}$ daily was given for 10 days and serum calcium failed to decrease. An infusion of $160 \mathrm{MRC}$ units porcine calcitonin also failed to lower the serum calcium. However, after the administration of carbimazole $30 \mathrm{mg}$ daily, the serum calcium fell rapidly (Fig. 1.). Urinary calcium and blood urea also returned to normal.

A sub-total thyroidectomy was performed and 4 normal parathyroids were identified. Four years later the patient was euthyroid, normocalcaemic and had normal renal function.

\section{Discussion}

The incidence of hyperparathyroidism in thyrotoxicosis is reported to be 10 times greater than in the general population (Parfitt and Dent, 1970). It is therefore necessary to exclude co-existing parathyroid disease in thyrotoxic patients presenting with hypercalcaemia.

The hydrocortisone suppression test is often used 


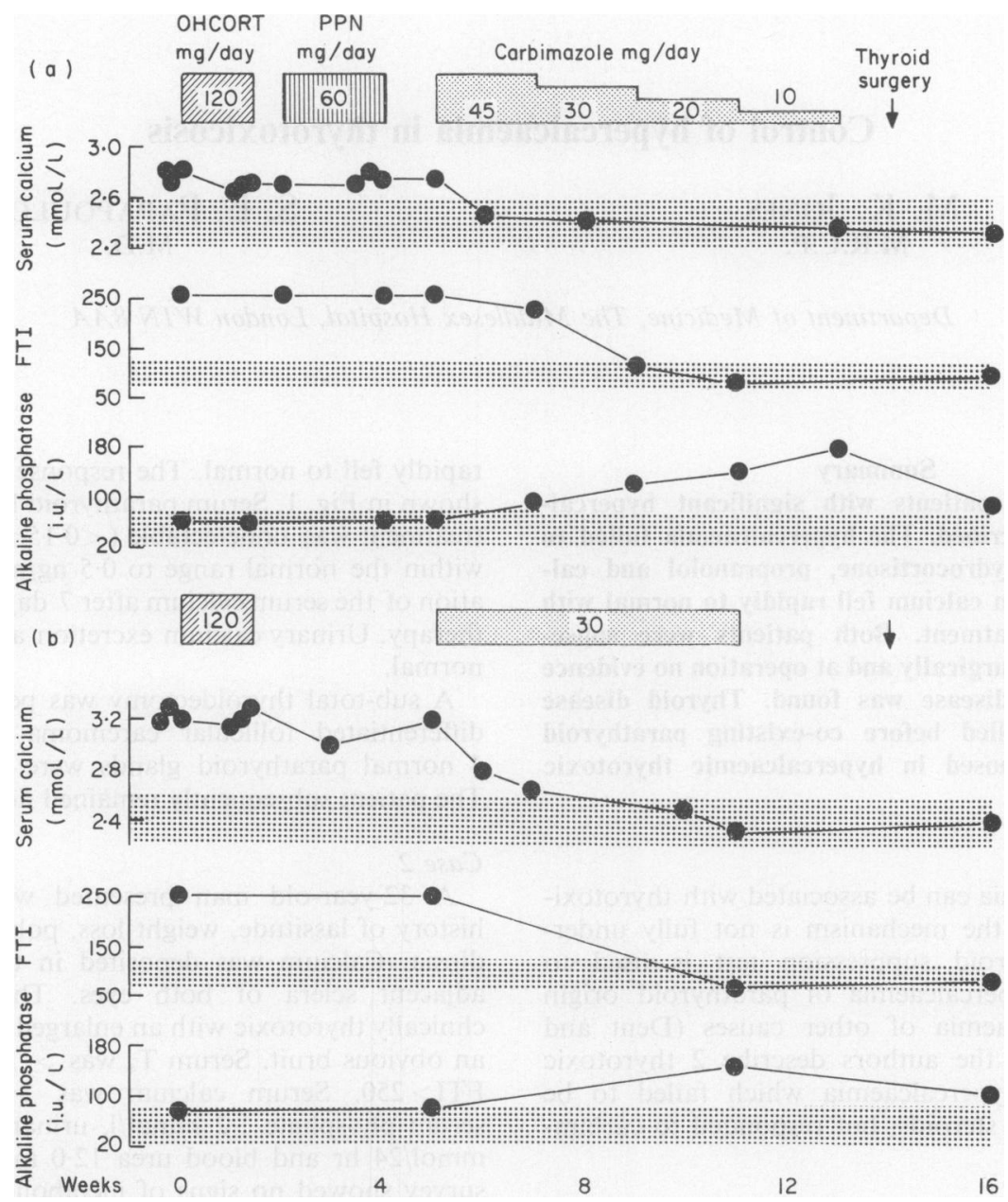

FIG. 1. The response of serum calcium, free thyroxine index (FTI) and alkaline phosphatase to treatment with hydrocortisone (OHCORT), propranolol (PPN) and carbimazole in 2 hypercalcaemic thyrotoxic patients. (a) Case 1, (b) case 2 . The shaded areas show the normal range.

to differentiate hypercalcaemia of parathyroid origin from hypercalcaemia of other causes (Dent and Watson, 1968). Fall of raised serum calcium after steroid administration has been reported in thyrotoxic patients (Sataline, Powell and Hamwi, 1962), but the 2 patients described here had significant hypercalcaemia which failed to decrease after the administration of hydrocortisone $120 \mathrm{mg}$ daily for 10 days, perhaps indicating the presence of hyperparathyroidism. There is a previous report of nonsuppressible hypercalcaemia in a thyrotoxic patient (David, Verners and Engel, 1962) but the authors consider that the dose of $100 \mathrm{mg}$ cortisone acetate given for 6 days might be inadequate.
In both patients described here, serum calcium fell rapidly after carbimazole treatment, and normal values appeared within 7 days in case 1 . This is in contrast to a previous suggestion that normalization of serum calcium in hypercalcaemic thyrotoxic patients might need 2 to 8 weeks of therapy (Twycross and Marks, 1970). The fall of serum calcium was associated with a rise of serum parathyroid hormone concentration and a fall of urinary calcium excretion to normal.

Case 2 was obviously thyrotoxic but the high serum calcium concentration presented also a management problem. Blood urea was raised, calcium was deposited in the cornea and adjacent sclera of both 
eyes and there was a danger of permanent renal damage. Intravenous calcitonin did not produce a fall in serum calcium contrary to a previous report (Buckle, Mason and Middleston, 1969). The response to carbimazole was impressive and this, together with a high fluid intake, is probably satisfactory for the management of most patients.

Other measures which have been reported to be effective in suppressing serum calcium in thyrotoxicosis include the administration of phosphate and propranolol. Rude et al (1976) described suppression of serum calcium in thyrotoxic patients treated with oral propranolol, but it should be noted that an anti-thyroid drug was administered at the same time; propranolol had no effect on serum calcium when given to case 1 in the present study.

The incidence of hypercalcaemia in thyrotoxicosis has been estimated to be as high as $22 \%$ (Baxter and Bondy, 1966) but this may be an overestimate. Overall, there is an increase in the mean serum calcium concentration in hyperthyroid patients, even within the normal range (Bouillon and De Moor, 1974). Although co-existing parathyroid disease is relatively more common in these subjects, the aetiology of the elevated serum calcium remains obscure. It has been attributed to an increased bone turnover although this may be an oversimplification as it does not explain why only a small proportion of patients develop hypercalcaemia, unless they are immobile or have developed renal insufficiency. The degree of thyroid overactivity does not seem to be a major factor as Gordon et al (1974) were unable to demonstrate a relationship between serum calcium and thyroid hormone concentrations in hyperthyroid patients. It has been proposed that a small proportion of patients have bone collagen which is particularly sensitive to thyroid hormone activity and it is this group who become hypercalcaemic (Askenasi and Demeester-Mirkine, 1975).

The increased bone turnover in thyrotoxicosis has also been implicated in the elevation of serum alkaline phosphatase found in thyrotoxic patients (Clerkin et al., 1964). In the present patients the alkaline phosphatase was initially normal but rose on treatment with carbimazole, probably indicating the replenishment of bone calcium stores when plasma thyroid hormone concentrations fell.

In hypercalcaemic thyrotoxic patients, the thyroid disease must be controlled before the diagnosis of co-existing parathyroid disease is made.

\section{Acknowledgments}

We thank Dr J.L.H. O'Riordan for permitting us to report these cases.

\section{References}

Askenasi, R. \& Demeester-Mirkine, N. (1975) Urinary excretion of hydroxyl glycosides and thyroid function. Journal of Clinical Endocrinology and Metabolism, 40, 342.

BAXTER, J.D. \& BondY, P.K. (1966) Hypercalcemia of thyrotoxicosis. Annals of Internal Medicine, 65, 429.

Bouillon, R. \& DE MooR, P. (1974) Parathyroid function in patients with hyper- or hypothyroidism. Journal of Clinical Endocrinology and Metabolism, 38, 999.

Buckle, R.M., Mason, A.M.S. \& Middleton, J.E. (1969) Thyrotoxic hypercalcaemia treated with porcine calcitonin. Lancet, i, 1128.

Clerkin, E.P., Haas, H.G., Mintz, D.H., Meloni, C.R. \& CANARY, J.J. (1964) Osteomalacia in thyrotoxicosis. Metabolism, 13, 161.

David, N.J., Verner, J.V. \& Engel, F.L. (1962) The diagnostic spectrum of hypercalcemia. American Journal of Medicine, 33, 88.

Dent, C.E. \& Watson, L. (1968) The hydrocortisone test in primary and tertiary hyperparathyroidism. Lancet, 2, 662.

Gordon, D.L., Suvanich, S., Erviti, V., Schwartz, M.A. \& Martinex, C.J. (1974) The serum calcium level and its significance in hyperthyroidism: a prospective study. American Journal of the Medical Sciences, 268, 31.

ParfitT, A.M. \& Dent, C.E. (1970) Hyperthyroidism and hypercalcemia. Quarterly Journal of Medicine, 39, 171.

Rude, R.K., Oldham, S.B., Singer, F.R. \& Nicoloff, J.T. (1976) Treatment of thyrotoxic hypercalcemia with propranolol. New England Journal of Medicine, 294, 431.

Sataline, L.R., Powell, C. \& Hamwi, S.J. (1962) Suppression of the hypercalcemia of thyrotoxicosis by corticosteroids. New England Journal of Medicine, 267, 646.

Twycross, R.G. \& MARKs, V. (1970) Symptomatic hypercalcaemia in thyrotoxicosis. British Medical Journal, 2, 701. 